\title{
CARACTERIZAÇÃO DO BIOCHAR OBTIDO A PARTIR DO PROCESSO DE CRAQUEAMENTO TÉRMICO E TERMOCATALÍTICO EM ESCALA PILOTO DO LODO DE ESGOTO ORIUNDO DA ESTAÇÃO DE TRATAMENTO DE ESGOTO (ETE) VILA DA BARCA ATRAVÉS DE ANÁLISES FÍSICO-QUÍMICAS E MEV-EDS
}

\author{
H. G. S. SOUZA ${ }^{1}$, N. T. MACHADO ${ }^{1}$, H. S. ALMEIDA², N. M. MENDONÇA², L. \\ PEREIRA $^{3}$ \\ ${ }^{1}$ Universidade Federal do Pará, Faculdade de Engenharia Química \\ ${ }^{2}$ Universidade Federal do Pará, Faculdade de Engenharia Sanitária e Ambiental \\ ${ }^{3}$ Universidade Federal do Pará, Programa de Pós-Graduação em Engenharia de \\ Recursos Naturais da Amazônia \\ E-mail para contato: helenagss@live.com
}

\begin{abstract}
RESUMO - O lodo, resíduo oriundo de estações de tratamento de esgoto (ETEs), caracteriza-se como uma biomassa de difícil manejo, de modo que sua crescente produção demanda formas alternativas de processamento que lhe deem finalidade ambientalmente adequada. Neste contexto as rotas de craqueamento térmico e termo catalítico tem se mostrado como formas promissoras de conversão desta biomassa em subprodutos de alto potencial energético e com grandes possibilidades de emprego em áreas diversas. Dentre os subprodutos damos ênfase ao Biochar, material carbonáceo que vem sendo cada vez mais estudado para a verificação de sua aplicabilidade como insumo agrícola para correção de solo, composto com alto poder de sequestro de gases responsáveis pelo efeito estufa, material adsorvente, dentre outros. Neste contexto, o presente trabalho vem caracterizar os Biochares oriundos das rotas de craqueamento térmico e termo catalítico em escala piloto do lodo de esgoto advindo da Estação de Tratamento de Esgoto (ETE) Vila da Barca da cidade de Belém através da Microscopia Eletrônica de Varredura acoplada ao Sistema de Energia Dispersiva (MEV-EDS) e análises físico-química.
\end{abstract}

\section{INTRODUÇÃO}

O lodo de esgoto é um resíduo oriundo das estações de tratamento de esgoto (ETE) que se caracteriza como o principal produto das reações químicas, bioquímicas e biológicas que ocorrem no tratamento de águas residuais urbanas, industriais ou agrícolas, onde predominam a matéria orgânica (VIEIRA, G. E., 2014), contendo todos os materiais sólidos não removidos durante o processo de tratamento de esgoto (VIANA, M., 2014). A produção desta biomassa 
vem sendo cada vez maior devido aos fatores limitantes da disposição de água e ao crescente número de domicílios ligados às estas estações, o que torna urgente a necessidade de encontrar novos fins a tal resíduo (GASGÓ, G., 2007), os quais devem estar de acordo com as disposições da Política Nacional de Resíduos Sólidos (lei 12.350/2010), a qual dispões sobre princípios, instrumentos e objetivos, assim como sobre diretrizes para a gestão integrada e ao gerenciamento de resíduos sólidos.

Dentre os inúmeros processos de conversão de biomassa, há os termoquímicos, que incluem o craqueamento térmico e termo-catalítico, onde são utilizadas temperaturas e/ou pressões elevadas para promover a alteração da estrutura química do material utilizado (KIM, K., et al. 2013) Tais rotas se mostram promissoras formas de decomposição de lodo de esgoto, resíduos gordurosos e resíduos têxteis (BOTTON et al, 2012). Neste processo são gerados três subprotudos: os gases não condensáveis, o produto líquido orgânico (PLO) e Biochar, cujas características são sensíveis às condições de operação sob as quais foram produzidos, como temperatura de reação, emprego de catalizador etc. Atualmente vários estudos tem-se voltado às aplicações do Biochar, que é um material carbonáceo poroso com grande quantidade de carbono fixo (LABEGALINI, A., 2013), o qual é oriundo especificamente da degradação térmica de biomassa. Segundo CROMBIE e MASEK (2015), o Biochar, quando aplicado incorporado ao solo, pode ter um significante impacto em suas quantidades de carbono orgânico, em suas capacidade de retenção de água e capacidade de permuta catiônica, em seu $\mathrm{pH}$ e ecologia microbiana, além de possuir capacidade de sequestrar gases estufa. Há ainda a possibilidade de emprego deste como material para adsorção de poluentes em meio aquoso, conforme o descrito por VIANA, M. (2015). Baseado nisto, este trabalho visa caracterizar os Biochares obtidos a partir dos processos de craqueamento térmico e térmico catalítico em escala piloto do lodo de esgoto bruto advindo da Estação de Tratamento de Esgoto (ETE) Vila da Barca da cidade de Belém através da Microscopia Eletrônica de Varredura acoplada ao Sistema de Energia Dispersiva (MEV-EDS) e análises físico-químicas.

\section{MATERIAIS E MÉTODOS}

\subsection{CRAQUEAMENTO TÉRMICO E TERMO CATALÍTICO}

A matéria prima foi coletada no sistema de tratamento de esgoto associado ao reator UASB+BFs da Estação de Tratamento de Esgoto Vila da Barca, onde toda a massa coletada foi submetida a secagem térmica em estufa com circulação de ar, SOC. FABBE. Ltda, MOD. 170 , a $100^{\circ} \mathrm{C}$ por um período de 72 horas e desagregamento da massa seca em moinho de bola, modelo M.B. 12X, WORK INDEK, CIMAQ. Também foi efetuada coleta e tratamento da gordura residual do Restaurante Universitário da Cidade Universitária Silveira Neto (Belém, PA), setor Básico. A gordura sofreu tratamento térmico para que fosse liquefeita e separada da água, posteriormente foi peneirada para a remoção de sólidos que em sua maioria consistiam em restos alimentares (feijão, macarrão, arroz, etc.). $\mathrm{O}$ catalizador $\left(\mathrm{CaCO}_{3}\right)$ passou por tratamento térmico de duas horas em Forno Mufla ZEZIMAQ - GP CIENTÍFICA, sendo calcinado até 1000 graus. Finalmente, foram efetuados dois experimentos no reator em escala piloto residente no Laboratório de Separações Térmicas (THERMTEK) da Faculdade de Engenharia Química da UFPA. Obtiveram-se os coque 1 
(experimento 1) e coque 2 (experimento 2). Ao experimento 1 o reator foi alimentado unicamente com o lodo seco, ao experimento 2 a alimentação consistiu em lodo seco, catalizador e gordura residual.

Tabela 1 - Parâmetros Operacionais e rendimento do Biochar dos experimentos 1 e 2

\begin{tabular}{r|c|c|} 
& Experimento 1 & Experimento 2 \\
\hline Massa de Lodo $(\mathrm{Kg})$ & 27 & 19 \\
\hline Massa de Catalizador $(\mathrm{Kg})$ & - & 6,7 \\
\hline Massa de Gordura $(\mathrm{Kg})$ & - & 1,3 \\
\hline Temp. de Craqueamento $\left({ }^{\circ} \mathrm{C}\right)$ & 438 & 327 \\
\hline Tempo Total de Processo $(\mathrm{min})$ & 150 & 210 \\
\hline Rendimento em Biochar $(\%)$ & 70 & 65
\end{tabular}

As amostras de Biochar obtidas foram mantidas em dessecador para que as variações em suas propriedades fossem poucas ou nenhuma. As análises realizadas foram de teor de cinzas, teor de umidade e condutividade elétrica. A investigação de suas morfologia e composição foi feita através de MEV-EDS.

\subsection{ANÁLISES FÍSICO-QUÍMICAS}

O teor de umidade foi determinado através da secagem do material a $103{ }^{\circ} \mathrm{C}$, onde foi verificada a variação de sua massa devido ao procedimento. O teor de cinzas se utilizou do aquecimento a $600{ }^{\circ} \mathrm{C}$ do material em Forno Mufla, onde também se investigou a variação de massa da amostra. As medidas de condutividade elétrica foram obtidas com condutivímetro de bancada QUIMIS, modelo STD Q405M.

\subsection{MEV-EDS}

Para obtenção das imagens de microscopia eletrônica de varredura (MEV-EDS), as amostras foram fixadas em stubs, com fita carbono adesivo e metalizadas aplicando um fino filme de ouro pelo método de sputtering para tornar a superfície das amostras condutora. A análise foi realizada utilizando um microscópio TM 3000 HITACHI com sistema de EDS acoplado.

\section{RESULTADOS E DISCUSSÕES}

A Tabela 2 mostra os resultados para teor de umidade, teor de cinzas e condutividade elétrica aos coque 1, coque 2 e ao lodo seco em estufa, para efeitos comparativos.

Tabela 2 - Resultado das análises físico-quimicas dos coque 1 e coque 2 Amostra Teor de umidade (\%) Teor de cinzas (\%) Condutividade elétrica $(\mu \mathrm{S} / \mathrm{cm})$

\begin{tabular}{l|c|c|c|}
\hline Coque 1 & 0,8 & 60,66 & 3,17 \\
\hline Coque 2 & 0,6 & 50,76 & 13,00 \\
\hline Lodo seco & 7 & 48,89 & 4,24 \\
\cline { 2 - 3 }
\end{tabular}




\section{C $\$ B E Q$ \\ CONGRESSO BRASILEIRO DE ENGENHARIA QUÍMICA EM INICIAÇÃO CIENTÍFICA}

Ao observarmos o teores de umidade dos coque $1(0,8 \%)$ e coque $2(2 \%)$, verificamos que a quantidade de água remanescente no carvão, ao ser comparada com a matéria prima seca, é muito pequena. Os teores de cinzas apresentados por ambos os coques, no entanto, foram maiores que o registrado ao Lodo seco, onde atestamos ainda uma variação entre os valores obtidos, onde o coque 1 apresentou teor de cinzas de 60,66\%, enquanto o coque 2 de $50,76 \%$, o que pode ser explicado pelo fato de que o processo de craqueamento referente a produção do primeiro atingiu temperaturas mais elevadas, ou devido a composição diferente do material empregado na produção do segundo (seco+gordura residual $+\mathrm{CaCO}_{3}$ ). Quanto a condutividade elétrica, observou-se sua redução do lodo seco $(4,24 \mu \mathrm{S} / \mathrm{cm})$ ao coque $1(3,17$ $\mu \mathrm{S} / \mathrm{cm}), \mathrm{o}$ coque 2 , por sua vez, apresentou valor mais elevado $(13,00 \mu \mathrm{S} / \mathrm{cm})$, que também pode ser explicado pela composição do material empregado na obtenção do coque 2.

As imagens obtidas a partir do MEV são ilustradas na Imagem 1 e a composição dos carvões fornecida pelo EDS acoplado são apresentadas na tabela 3.

Imagem 1 - Micrografias os coque 1, coque 2 e lodo seco ampliadas 120 x e 500 x

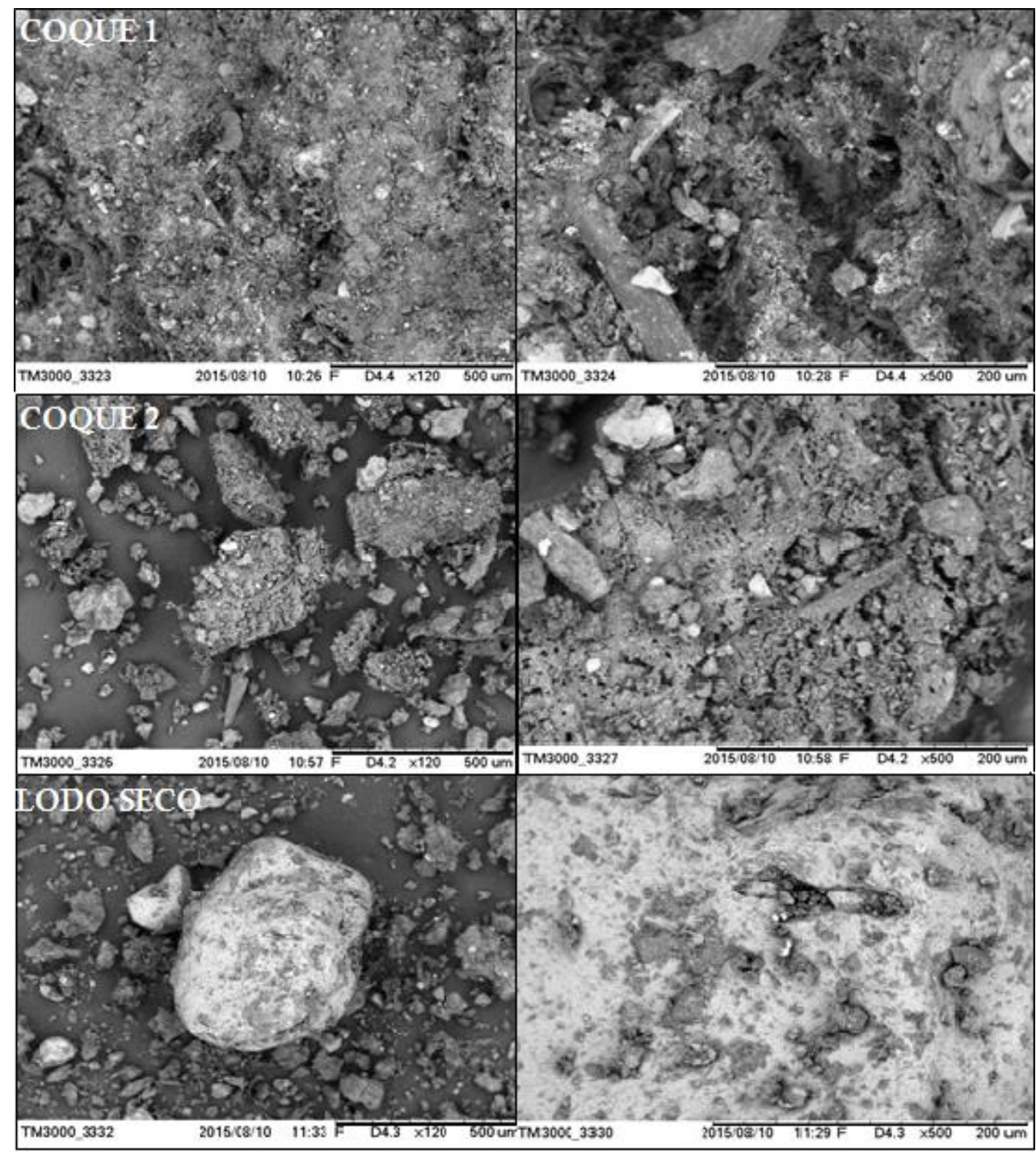


As imagens obtidas pelo MEV mostraram que os Biochares obtidos apresentaram partículas mais agregadas quando comparadas às do Lodo seco e com materiais mais fibrosos, onde as micrografias mostraram que os coque 1 e coque 2 apresentaram porosidade perceptível. O coque 2, em específico, apresentou um Biochar de superfície mais densa e com poros bem definidos, resultado que pode ser justificado pela baixa temperatura de craqueamento referente ao experimento $2\left(327^{\circ} \mathrm{C}\right)$, o que pode indicar que as cadeias longas de ácidos graxos da gordura residual não foram quebradas de modo efetivo.

Tabela 3- Resultados médios da análise de EDS dos coque 1, coque 2 e Lodo seco

Composição química das amostras (\%)

\begin{tabular}{c|c|c|c|c|c|c|c|c|c|c|c} 
Amostra & \multicolumn{1}{c|}{$\mathrm{C}$} & $\mathrm{O}$ & $\mathrm{Al}$ & $\mathrm{Si}$ & $\mathrm{Fe}$ & $\mathrm{S}$ & $\mathrm{Ca}$ & $\mathrm{Mg}$ & $\mathrm{Na}$ & $\mathrm{P}$ & $\mathrm{K}$ \\
\hline $\begin{array}{c}\text { Lodo } \\
\text { seco }\end{array}$ & 50,37 & 39,01 & 0,78 & 9,46 & 0,08 & 0,18 & 0,05 & 0,00 & 0,00 & 0,00 & 0,00 \\
\hline Coque 1 & 57,69 & 31,51 & 2,65 & 3,29 & 0,90 & 0,75 & 1,31 & 0,24 & 0,00 & 1,62 & 0,00 \\
\hline Coque 2 & 31,54 & 47,19 & 4,29 & 4,32 & 1,26 & 1,55 & 0,61 & 0,00 & 5,72 & 0,19 & 0,28 \\
\cline { 2 - 11 }
\end{tabular}

Os elementos mais abundantes nos três materiais analisados foram o carbono (C), oxigênio $(\mathrm{O})$ e o silício $(\mathrm{Si})$, onde os coque 1 e 2 mostraram, ainda, abundância de alumínio $(\mathrm{Al})$. Concentrações consideráveis de cálcio $(\mathrm{Ca})$, fósforo $(\mathrm{P})$ e ferro $(\mathrm{Fe})$ também foram atestadas. Vale ressaltar que a concentração de carbono apresentada pelo coque 1 foi quase $o$ dobro da apresentada pelo coque 2 .

\section{CONCLUSÃO}

A rota de craqueamento térmico e termo catalítico se mostrou efetiva na conversão da biomassa utilizada sozinha e associada ao resíduo gorduroso, expandindo as possibilidades de seu emprego e corroborando o apresentado na literatura, como o descrito por Botton et al (2012). No que tange ao Biochar, o mesmo apresentou altos rendimentos tanto ao experimento 1(coque 1) quanto ao 2 (coque 2). Verificamos a abundância em carbono e outros elementos inorgânicos como o cálcio, de modo que o biochar produzido apresente a possibilidade de ser aplicado em solos visando melhorar sua produtividade, seu estoque de carbono e mesmo a filtração da água de percolação, como o explicado por Lehmann e Joseph (2015). O material apresentou também porosidade evidente, o que pode viabilizar seu uso como material adsorvente na forma de biocarvão, semelhante ao desenvolvido por Viana (2015), estudo que será desenvolvido em prosseguimento ao presente trabalho a fim de investigar a capacidade adsorvente do mesmo em suas formas bruta e ativada.

\section{AGRADECIMENTOS}

Os autores desejam expressar seus sinceros agradecimentos ao Programa de PósGraduação em Engenharia de Recursos Naturais da Amazônia - PRODERNA/UFPA e ao Programa de Integrado de Apoio ao Ensino, Pesquisa e Extensão - PROINT 1620037780895 (Edital № 004/2015 - PROEG/UFPA) pelo apoio financeiro. 


\section{REFERÊNCIAS}

BOTTON, V.; RIVA, D.; SIMIONATTO, E. L.; WIGGERS, V. R.; ENDLER, L.; MELER, H. F.; BARROS, A. A. C. Craqueamento Térmico-Catalítico da mistura óleo de fritura usado-lodo de estamparia têxtil para produção de óleo com baixo índice de acidez. Quim. Nova, v. 35, n. 4, p. 677-682, 2012.

BRASIL, Lei Federal No 12.350, de 2 de agosto de 2010. Política Nacional de Resíduos sólidos (PNRS). Brasília, v. 1, 2010.

CROMBIE, K. and MAŠEK, O. Pyrolysis biochar systems, balance between bioenergy and carbon sequestration. GCB Bioenergy, v. 7, p. 349-361, 2015.

GASCÓ, G.; CUETO, M. J.; MENÉNDEZ, A. The effect of acid treatment on the pyrolysis behavior of ewage sludges. J. of Analytical and Applied Pyrolysis, v. 80, n. 2, p. 496$501,2007$.

KIM, K. H., KIM, T. S., LEE, S. M., CHOI, D., YEO, H., CHOI, I. G., \& CHOI, J. W. Comparison of physicochemical features of biooils and biochars produced from various woody biomasses by fast pyrolysis. Renewable Energy, Oxford, v. 50, p. 188-195, 2013.

LABEGALINI, A. Obtenção de biochar a partir da pisólise rápida da torta de pinhão-manso: uso como adsorvente e suporte. Dissertação de Mestrado. Universidade Federal de Lavras, 2013.

LEHMANN, J.; JOSEPH, S. (Ed.). Biochar for environmental management: science, technology and implementation. Routledge, 2015.

VIANA, M. M. Obtenção e utilização de produtos de pirólise do lodo de esgoto para adsorção de poluentes em meio aquoso. Tese de Doutorado. Universidade de São Paulo, 2013.

VIEIRA, G. E., e ALEXANDRE, G. P. Tratamento, caracterização e obtenção de bio-óleo combustível a partir da pirólise termocatalítica de lodo de esgoto doméstico. Rev. Liberato, v. 14, p. 01- $\underline{104}$, 2014./ 